\title{
An international perspective on the acceptability and sustainability of electroconvulsive therapy
}

\author{
Daniel Maughan ${ }^{1}$ and Andrew Molodynski ${ }^{2}$
}

${ }^{1}$ Advanced Trainee in Psychiatry, Oxford Health NHS Foundation Trust, Department of Psychiatry, Oxford University, Oxford, UK, email drdanielmaughan@gmail.

${ }^{2}$ Consultant Psychiatrist, Research Fellow, Oxford Health NHS Foundation Trust, Department of Psychiatry, Oxford University Oxford, UK
There is robust evidence that electroconvulsive therapy is an effective treatment for some mental illnesses. Despite this, its use remains controversial and is declining in some countries, with a consequent loss of skills and knowledge. This, and the view of it as a 'treatment of last resort', may undermine its sustainability.

To be sustainable, an intervention requires evidence for its effectiveness and manageable financial costs; its environmental impacts should also be addressed (Yarlagadda et al, 2014). Sustainability additionally depends upon wider factors, such as acceptability, stigma and workforce development. The future use of electroconvulsive therapy (ECT) may be in question not because of its clinical effectiveness or cost but because of these wider factors.

A health technology assessment by Greenhalgh et al (2005) combined three systematic reviews, two looking at randomised evidence and one looking at non-randomised evidence. The authors concluded that, for a variety of conditions, ECT was probably more effective than pharmacotherapy in the short term and better than repetitive transcranial magnetic stimulation. A meta-analysis of 18 studies found that ECT was significantly more effective than pharmacotherapy for depressive illness (UK ECT Review Group, 2003). ECT is likely to be the most effective intervention available in mental healthcare in some circumstances. It has also been shown to be as cost-effective as pharmacotherapy (see Greenhalgh et al, 2005). Given its proven clinical effectiveness and cost-effectiveness, ECT should continue to be recognised as an important part of mental healthcare provision.

Internationally, rates of use of ECT vary significantly, from 0.11 per 10000 population (Poland) to 4.30 (Norway) and 5.10 (USA) (Leiknes et al, 2012). Low- and middle-income countries tend to have lower national rates than higher-income countries, with overall rates for Africa at 1.26 per 10000 and for Thailand at 1.15 per 10000 (Leiknes et al, 2012). This may reflect availability. For example, in Russia ECT facilities are available in services covering only $22 \%$ of the population (Nelson, 2005). On the other hand, ECT rates per admission are high in Africa (21-28\%) and Nepal (26\%), with much lower rates in the USA $(0.4 \%)$ and Europe $(0.6 \%)$ (Little, 2003; Leiknes et al, 2012). Therefore, although overall use is higher in Europe and America, there is actually a higher rate of ECT use per identified patient in many lower-income countries.
Few would disagree that ECT was overused in the past. However, its use in the USA and the UK has continued to decline, to the point where concerns are now being raised as to whether it might be being underused. In the UK, the most recent available evidence indicates that the annual rate of administration of ECT per admission decreased from $35 \%$ in 1956 to $2.2 \%$ from 1991 onward - and this with many fewer overall admissions (Lambe et al, 2014). Moreover, ECT is used increasingly late in treatment plans in the UK (Lambe et al, 2014). In the USA, similar reductions have been noted alongside the reduced availability of ECT (Kramer, 1999). Some have suggested that this might be linked to negative perceptions of ECT on the part of the public or of staff (Kramer, 1999). In the Netherlands, a study reported that the majority of psychiatrists had reservations about considering ECT as a treatment of first, second or third choice for elderly patients with depression (van der Wurff et al, 2004). Other suggestions for this trend include negative and stigmatising perceptions of ECT, lack of consensus on use and neglect on the part of psychiatrists themselves (Eranti \& McLoughlin, 2003).

Concerns have also been raised about whether increasingly complex laws and regulations, driven partly by negative public pressure, are reducing the use of ECT (Finch et al, 1999). Two bills in Texas (a state with active use of the death penalty) attempted either to ban the use of ECT completely or to ban its use for those over 65 years of age (Finch et al, 1999). In the UK, extra safeguards have been placed on the use of ECT under the Mental Health Act in recent years.

\section{How unacceptable is ECT?}

The perception of ECT is poor among patients and the wider public. In a Swiss survey, the public rated ECT as the least helpful mental health treatment, with only $1 \%$ considering it to be effective (see Lauber et al, 2005). Another public survey reported that $57 \%$ considered ECT a harmful treatment and only a small number $(1.2 \%)$ were in favour of its use. Predictors of negative attitudes were younger age and greater degree of contact with people who are mentally ill (Lauber et al, 2005). These negative attitudes are also present among patients. A survey of psychiatric patients in Pakistan found that 37\% thought ECT was inhumane (Arshad et al, 2007). A study in Iran, however, found that undergoing ECT improved patients' attitude to it, regardless of treatment outcome (Malekian et al, 2009). 


\section{Why is ECT deemed unacceptable?}

There are many reasons why ECT provokes such negative attitudes, and they fall into three main categories: mechanism of treatment; side-effects; and stigma. Internationally, there remain concerns that the mode of therapy uses electricity (Andrade \& Thyagarajan, 2007) and an all-too-easy comparison can be made between ECT and the electric chair. This is perhaps not helped by the fact that, across Asia, sine-wave ECT is still being commonly administered, bilateral electrode placement is often the default, electroencephalographic (EEG) monitoring is uncommon, and often no formal training is available (Chanpattana et al, 2010). In Russia, EEG and seizure quality are rarely monitored and fewer than $20 \%$ of ECT treatments are modified with anaesthesia (Nelson, 2005).

Side-effects are understandably a major reason for concern about ECT. Cognitive side-effects are a common worry; one systematic review found that at least one-third of patients report significant memory loss after treatment (Rose et al, 2003).

There are other non-evidence-based factors that affect the acceptability of ECT. The most important is stigma, which has been fuelled by the media. Negative depictions of ECT are found in newspapers (Arshad et al, 2007) and in films. Of 22 Hollywood films that featured the use of ECT, 18 depicted negative outcomes, including zombification and death (McDonald \& Walter, 2009). In Hindu cinema, each of 13 films which included ECT depicted it being given by force. The portrayals were inaccurate and distorted, with ECT being administered to punish, to change a person's identity or to induce insanity (Andrade et al, 2010).

\section{What can we do about this?}

There is a real danger that this poor impression of ECT is reducing its sustainability and that this effective treatment is being underused as a result. Ultimately, if the sustainability of ECT is challenged persistently enough it may cease to be available to those who would benefit from it. Prevailing attitudes of the public, patients and staff alike will need to change to reflect evidence rather than stigma and negative media portrayals. Different strategies to achieve this are likely to be effective in different groups.

Attitudes to ECT may benefit from giving greater voice to those who have experienced it personally (Rose et al, 2003; Arshad et al, 2007), as there is evidence that they are more in favour of it as a treatment (Malekian et al, 2009). Ten out of 12 studies in one systematic review found that patients who had had ECT would have it again and nine out of 16 studies found that most patients thought it was helpful (Rose et al, 2003).

What is clear is that more information needs to be provided by people who know most about it. Psychiatrists should know where to direct those who are uncertain about the benefits of ECT and who may have undue preconceptions. A useful source of information is the Royal College of Psychiatrists, notably its website (http://www. rcpsych.ac.uk/healthadvice/treatmentswellbeing/ ect.aspx). The use of 'STARS' (people who have had a treatment) is common in services for patients with personality disorder. Perhaps a similar system could be beneficial for those considering ECT.

There is evidence that training and knowledge enhancement can improve staff attitudes to ECT. Studies have indicated that staff education helps to reduce negative attitudes (Stevens \& Harper, 2007) and one study concluded that effectively educating staff about ECT would increase its appropriate use (Janicak et al, 1985). Staff education needs to be thought through carefully, however. One study found that simply watching a video about ECT did not alter students' attitudes (Benbow, 1990), but another suggested that change is possible if students both watch ECT being administered and receive a lecture (Kinnair et al, 2010).

The media have a crucial role in reducing negative perceptions of ECT among the general population. It has been suggested that changing the name of ECT could improve public attitudes. In one survey, the highest level of acceptability was found for the term 'electrostimulatory therapy' $(53 \%)$ and the least for 'electroconvulsive therapy' (9\%) (Andrade \& Thyagarajan, 2007). This may be because 'electrostimulatory therapy' is less obviously associated with the likelihood of harm and it emphasises the stimulatory effects of the treatment, whereas 'convulsive' draws parallels with epilepsy (Andrade \& Thyagarajan, 2007).

\section{Conclusions}

ECT is an effective treatment. It is important that we do not restrict its use because of damage to its acceptability as a treatment and as a result reduce its social sustainability. Evidence suggests that the outcome of ECT in non-consenting patients is equivalent to that seen in consenting patients (Wheeldon et al, 1999) so further restrictions on access could deny the benefits of an effective and safe treatment to those most at risk.

Mass media campaigns can reduce the stigma associated with mental illness (Clement et al, 2013) and these perhaps could be used to aid the cause of ECT. However, the first priority should be the education of professionals. It is important that psychiatrists base prescribing decisions upon evidence, as well as the patient's circumstances and preferences. Although stigma and negative attitudes will undoubtedly play a role, it is a professional's duty to minimise their effect. To do so, clinicians need to be supported to acknowledge and allay patients' fears. Initiatives such as the Royal College of Psychiatrists' ECTAS service, establishing robust, widely agreed clinical standards covering all aspects of service provision, are crucial in the defence of ECT as a humane treatment. Postgraduate psychiatric training authorities should require clinical competencies and skills in ECT, as this would address some of the antipathy for ECT resulting from lack of knowledge among professionals. Action must be taken to mitigate the effects of stigma and negative media portrayal that 
we are all familiar with in order to protect a valuable evidence-based treatment. One thing at least is clear: if we are to ensure the sustained availability of ECT, professionals working in mental health must actively counter the prevailing culture of increasing restrictions on its use.

\section{References}

Andrade, C. \& Thyagarajan, S. (2007) The influence of name on the acceptability of ECT: the importance of political correctness. Journal of Electroconvulsive Therapy, 23, 75-77.

Andrade, C., Shah, N. \& Venkatesh, B. K. (2010) The depiction of electroconvulsive therapy in Hindi cinema. Journal of Electroconvulsive Therapy, 26, 16-22.

Arshad, M., Arham, A. Z., Arif, M., et al (2007) Awareness and perceptions of electroconvulsive therapy among psychiatric patients: a cross-sectional survey from teaching hospitals in Karachi, Pakistan. BMC Psychiatry, 7, 27.

Benbow, S. M. (1990) Medical students and electroconvulsive therapy: their knowledge and attitudes. Convulsive Therapy, 6 32-37.

Chanpattana, W., Kramer, B. A., Kunigiri, G., et al (2010) A survey of the practice of electroconvulsive therapy in Asia. Journal of Electroconvulsive Therapy, 26, 5-10.

Clement, S., Lassman, F., Barley, E., et al (2013) Mass media interventions for reducing mental health-related stigma. Cochrane Database of Systematic Reviews, 7, CD009453.

Eranti, S. V. \& McLoughlin, D. M. (2003) Electroconvulsive therapy state of the art. British Journal of Psychiatry, 182, 8-9.

Finch, J. M., Sobin, P. B., Carmody, T. J., et al (1999) A survey of psychiatrists' attitudes toward electroconvulsive therapy. Psychiatric Services, 50, 264-265.

Greenhalgh, J., Knight, C., Hind, D., et al (2005) Clinical and cost-effectiveness of electroconvulsive therapy for depressive illness, schizophrenia, catatonia and mania: systematic reviews and economic modelling studies. Health Technology Assessment, 9 $1-156$

Janicak, P. G., Mask, J., Trimakas, K. A., et al (1985) ECT: an assessment of mental health professionals' knowledge and attitudes. Journal of Clinical Psychiatry, 46, 262-266.
Kinnair, D., Dawson, S. \& Perera, R. (2010) Electroconvulsive therapy: medical students' attitudes and knowledge. The Psychiatrist, 34, 54-57.

Kramer, B. A. (1999) Use of ECT in California, revisited: 1984-1994. Journal of Electroconvulsive Therapy, 15, 245-251.

Lambe, S., Mask, J., Trimakas, K. A., et al (2014) Trends in use of electroconvulsive therapy in south London from 1949 to 2006. Journal of Electroconvulsive Therapy, 30, 309-314.

Lauber, C., Nordt, C., Falcato, L., et al (2005) Can a seizure help? The public's attitude toward electroconvulsive therapy. Psychiatry Research, 134, 205-209.

Leiknes, K. A., Schweder, L. J.-V. \& Høie, B. (2012) Contemporary use and practice of electroconvulsive therapy worldwide. Brain and Behavior, 2, 283-344.

Little, J. D. (2003) ECT in the Asia Pacific region: what do we know? Journal of Electroconvulsive Therapy, 19, 93-97.

Malekian, A., Amini, Z., Maracy, M. R., et al (2009) Knowledge of attitude toward experience and satisfaction with electroconvulsive therapy in a sample of Iranian patients. Journal of Electroconvulsive Therapy, 25, 106-112.

McDonald, A. \& Walter, G. (2009) Hollywood and ECT.

International Review of Psychiatry, 21, 200-206.

Nelson, A. I. (2005) A national survey of electroconvulsive therapy use in the Russian Federation. Journal of Electroconvulsive Therapy, 21, 151-157.

Rose, D., Fleischmann, P., Wykes, T., et al (2003) Patients' perspectives on electroconvulsive therapy: systematic review. BMJ (Clinical Research), 326, 1363.

Stevens, P. \& Harper, D. J. (2007) Professional accounts of electroconvulsive therapy: a discourse analysis. Social Science and Medicine, 64, 1475-1486.

UK ECT Review Group (2003) Efficacy and safety of electroconvulsive therapy in depressive disorders: a systematic review and meta-analysis. Lancet, 361, 799-808.

van der Wurff, F. B., Stek, M. L., Hoogendijk, W. J., et al (2004)

Discrepancy between opinion and attitude on the practice of ECT by psychiatrists specializing in old age in the Netherlands. Journal of Electroconvulsive Therapy, 20, 37-41.

Wheeldon, T. J., Robertson, C., Eagles, J. M., et al (1999) The views and outcomes of consenting and non-consenting patients receiving ECT. Psychological Medicine, 29, 221-223.

Yarlagadda, S., Maughan, D., Lingwood, S., et al (2014)

Sustainable psychiatry in the UK. Psychiatric Bulletin, 38, 285-290.

MENTAL HEALTHLAW PROFILES

\title{
Mental health law profiles
}

\author{
George Ikkos
}

Consultant Psychiatrist in Liaison Psychiatry, Royal National Orthopaedic Hospital, London, UK, emailikkos@doctors.org.uk
In this issue we sail to three countries that provide the Atlantic border at the western end of Europe: France, Ireland and Portugal.

Readers may be surprised that until recently the land of liberté and the 'rights of man' (France) fell short of complying with the standards of the European Convention on Human Rights with respect to the compulsory detention and treatment of people with mental disorders. This former gap is unlikely to have surprised Michel Foucault, the author of History of Madness (2006; originally published in 1961 as Folie et déraison: Histoire de la folie à l'âge classique). He was a student of power and ideology and had a keen eye for inconsistencies between rhetoric and reality. Had he been around he might even have raised an eyebrow when reading the name of the office that has now been called in to address this shortcoming, namely 'the Judge for Liberties and Detention'! On the other hand, the repeated barbarous terrorist attacks on Paris in November 2015 underline how precarious the balance of liberty and safety is at all times.

Foucault's History of Madness, published in English in full only 45 years after its publication in France, is an original, radical and important piece of work. Restricted to a few sentences one can only caricature its rich content, which is in turns lucid, scholarly, surprising, complex and obscure and even overburdened with empty rhetoric sometimes. A main thesis of Foucault appears to be that although there has been a tradition of recognising mental illness in medicine and law since classical antiquity, this tradition played no significant part during the 'Age of Reason' (in the 17th and 18th centuries) when European societies (his evidence refers mainly to France but also England) undertook a 'great confinement' of 'unreason' in institutions, which, late in this period and during 